\title{
Establishing a framework for female germline initiation in the plant ovule
}

Jorge Lora ${ }^{1}$, Xiujuan Yang ${ }^{2}$, and Mathew R. Tucker ${ }^{2}$,

${ }^{1}$ Department of Subtropical Fruits, Instituto de Hortofruticultura Subtropical y Mediterránea 'La Mayora' (IHSM-UMA-CSIC), 29750

Algarrobo-Costa, Málaga, Spain

${ }^{2}$ School of Agriculture, Food and Wine, Waite Research Institute, The University of Adelaide, Glen Osmond, SA, Australia

*Correspondence: matthew.tucker@adelaide.edu.au

Received 27 November 2018; Editorial decision 29 April 2019; Accepted 2 May 2019

Editor: Sílvia Coimbra, University of Porto, Portugal

\begin{abstract}
Female gametogenesis in flowering plants initiates in the ovule, where a single germline progenitor differentiates from a pool of somatic cells. Germline initiation is a fundamental prerequisite for seed development but is poorly understood at the molecular level due to the location of the cells deep within the flower. Studies in Arabidopsis have shown that regulators of germline development include transcription factors such as NOZZLE/SPOROCYTELESS and WUSCHEL, components of the RNA-dependent DNA methylation pathway such as ARGONAUTE9 and RNADEPENDENT RNA POLYMERASE 6, and phytohormones such as auxin and cytokinin. These factors accumulate in a range of cell types from where they establish an environment to support germline differentiation. Recent studies provide fresh insight into the transition from somatic to germline identity, linking chromatin regulators, cell cycle genes, and novel mobile signals, capitalizing on cell type-specific methodologies in both dicot and monocot models. These findings are providing unique molecular and compositional insight into the mechanistic basis and evolutionary conservation of female germline development in plants.
\end{abstract}

Keywords: Arabidopsis, differentiation, epigenetics, expansion, germline, megasporogenesis, ovule. 


\section{Introduction}

During plant growth, cells must undergo numerous transitions to facilitate the essential developmental processes of germination, vegetative growth, and flowering (Bäurle and Dean, 2006). Changes in cell identity that define these developmental events have been intensively studied in the model plant Arabidopsis thaliana, mainly because it is small, easy to manipulate genetically, and provides access to a diverse range of genomic resources (Pang and Meyerowitz, 1987; Arabidopsis Genome Initiative, 2000). Many Arabidopsis genes have been identified that contribute to cell identity in different contexts, but a few key examples illustrate the basic mechanisms that facilitate plant cell differentiation. For example, in the shoot apical meristem, the identity of pluripotent stem cells is regulated by a negative feedback loop involving the signal peptide CLAVATA3 (CLV3), the CLAVATA1 (CLV1) receptor kinase, and the homeodomain transcription factor (TF) WUSCHEL (WUS), which is expressed in a group of cells termed the 'organizing centre' (Schoof et al., 2000). A similar TF receptorligand regulatory mechanism has been found in the root meristem involving the CLV3/ESR-like CLE40 peptide, the Arabidopsis CRINKLY4 (CR4) receptor-like kinase, and a homologue of WUS, WUSCHEL-RELATED-HOMEOBOX5 (WOX5) (Sarkar et al., 2007). Similar to WUS in the shoot, WOX5 is expressed in a group of root organizer cells called the 'quiescent centre'. Other regulators of root cell differentiation include the mobile transcription factor SHORTROOT, and its transcription factor target SCARECROW, which activate miRNA165/166 repressors as part of an elegant pathway that involves plasmodesmata and intercellular signalling to control xylem and endodermis development (Di Laurenzio et al., 1996; Koizumi et al., 2012). Moreover, in the epidermis of leaves and roots, transcriptional regulators such as GLABRA1 (R2R3- MYB) and GLABRA2 (homeobox-leucine zipper), bHLH proteins, and the WD-40 protein TRANSPARENT TESTA GLABRA 1 act in multimeric complexes to control hair formation and patterning in specific cell types (Schiefelbein, 2003). In general, these pathways involve a combination of organizer and response cells that interact via signals to cue differentiation of distinct cell types and tissues.

Critical differentiation events also take place during reproductive development. The flower is one of the last structures to form during plant growth, but integrates an array of cell specification and differentiation events in a relatively short time frame. This is particularly evident in the ovules and anthers, where germline cells differentiate from pools of sporophytic (somatic) cells and quickly transition towards a gametophytic phase (Schmidt et al., 2015). The germline cells, known as the microspore mother cell (MiMC) in the anther and megaspore mother cell (MeMC) in the ovule, are predisposed to initiate meiosis and reduce their chromosome number by half, a critical requirement for stable sexual reproduction. The capacity to differentiate a germline cell, promote its entry into meiosis, and support its development into a haploid phase highlights a specialized type of plant cell differentiation; one that shares some similarities with other meristem types and is highly conserved amongst plant species (Grossniklaus, 2011).

Unlike male tissues where multiple MiMCs will initiate in each anther, only a single MeMC will typically arise in each ovule. The plant ovule consists of sporophytic tissues including a proximal funiculus, central chalaza, and distal nucellus surrounded by integuments (Fig. 1). The transition from a somatic cell to a germline precursor occurs within the nucellus (Maheshwari, 1950), usually beginning with expansion of a somewhat ambiguously termed 'archesporial cell'. This cell or one of its products will give rise to a single MeMC that subsequently undergoes meiosis to produce four meiotic products in a process also referred to as 
megasporogeneis (Pinto et al., 2019). Only one of the meiotic products, the functional megaspore, will initiate the subsequent stages of germline development (megagametogenesis) and the other three megaspores degenerate. This contrasts with MiMC development in the anther where all four meiotic products become viable pollen grains.

Considerable knowledge has been generated regarding male germline development in Arabidopsis and rice, and this has recently been reviewed (Lockhart, 2014; Russell and Jones, 2015; Vogler et al., 2017). Although the same amount of knowledge is lacking in regards to female germline development, recent studies provide key insight into the pathways involved. In this review, we explore these findings in relation to key regulatory mechanisms involved in female germline formation in Arabidopsis and angiosperms in general. We discuss (i) cues that influence the number of germline cells forming in the ovule; (ii) morphological features that define germline formation; and (iii) factors that may influence the privileged location of the germline cell.

\section{Megasporogenesis: there can be only one... most of the time}

Many studies in diverse angiosperms have provided a descriptive summary of megasporogenesis, highlighting the remarkably conserved nature of the process (Tilton and Lersten, 1981; Kennell and Horner, 1985; Bajon et al., 1999; Russell, 2001). Indeed, only one MeMC is typically reported in most angiosperms and gymnosperms. This is illustrated by the examples of the gymnosperm Larix decidua (larch; Fig. 2A), the monocot Hordeum vulgare (barley; Fig. 2C), the early divergent angiosperm Annona cherimola (cherimoya; Fig. 2D), the model Brassicaceae Arabidopsis (Fig. 2E), and the Asteraceae member Hieracium pilosella (mouse-ear hawkweed; Fig. 2G). However, multiple MeMCs have been reported in species such as Trimenia moorei, which belongs to the ancient angiosperm clade Austrobaileyales (Bachelier and Friedman, 2011). This feature, can also be observed in atypical gymnosperms such as Gnetum (Fig. 2B) where up to 12 MeMCs form. Some of these cells degenerate, yet around five female MeMCs enter meiosis (Takaso and Bouman, 1986). In other specialized cases, such as Hieracium aurantiacum (orange hawkweed; Fig. 2F), multiple 'germline-like' cells can be observed in close proximity to a typical MeMC. These cells are called aposporous initials (Als) and contribute to the process of asexual seed development (apomixis). It is unlikely, however, that these Al cells are extra MeMCs, since compositional and molecular studies suggest they share greater similarity with the functional megaspore than the MeMC (Tucker et al., 2003; Juranic et al., 2018).

Based on cytological studies, one of the key differences during megasporogenesis in angiosperms is the nucellus layer surrounding the female germline. This consists of several epidermal layers in crassinucellate ovules (e.g. Annona species; Fig. 2D) or a single epidermal nucellus layer in tenuinucellate ovules (e.g. Arabidopsis and Hieracium; Fig. 2E-G). The crassinucellate ovule has been considered the ancestral type of ovule in angiosperms (Sporne, 1969). It is generally found in living gymnosperms such as Pinus, Larix, and Gnetum (Fig. 2A, B; Takaso and Bouman, 1986; Fiordi, 1987), basal/earlydivergent angiosperms (e.g. Annona; Fig. 2D; Endress, 2011; Lora et al., 2017), and in cereal monocots (Fig. 2C; Rudall, 1997), although this is debated in species such as barley depending on the developmental stage. In contrast, tenuinucellate ovules are found in evolutionarily derived angiosperms such as the eudicot Arabidopsis (Fig. 2E; Bajon et al., 1999; Endress, 2011). The nucellus is an intriguing tissue, 
fulfilling roles in germline development, nutrient flow, and mechanical support (see Wilkinson et al., 2018 and Lu and Magnani, 2018 for recent reviews).

\section{Diverse factors influence germline formation}

Apart from genes identified via genetic screens for reduced fertility, details of the molecular and genetic mechanisms underlying megasporogenesis have been difficult to dissect. Indeed, most of the classic megasporogenesis-related genes were reported in Arabidopsis some time ago (Schiefthaler et al., 1999; Yang et al., 1999; Gross-Hardt et al., 2002). More recently, progress has been facilitated through improved microscopic and genomic technologies, and details of these pathways and their role during megasporogenesis are considered below (Fig. 3). Among them, the KNUCKLES (KNU) gene has been used extensively as a marker of MeMC identity (Payne et al., 2004; Tucker et al., 2012a). KNU encodes a $\mathrm{C} 2 \mathrm{H} 2$ zinc-finger protein involved in the basal pattern elements along the proximal- distal axis of the Arabidopsis gynoecium prior to the initiation of female germline development (Payne et al., 2004). Although KNU has been shown to accumulate in the MeMC and possibly even the archesporial cell, its role in MeMC development remains unknown.

\section{SRNA pathways: a possible trigger for germline development}

At early developmental stages the morphology and size of most ovule cells (particularly those in the sub-epidermal L2 layer) are similar, leading to the suggestion that multiple cells have the potential to become an MeMC (Nonomura, 2003). However, differences in cell volume appear relatively quickly once germline development initiates; in Arabidopsis, L2 ovule cells increase in volume before stabilizing at the flanks of a centrally positioned germline precursor, the archesporial cell, which continues to increase in volume and becomes the MeMC (Fig. 1; Lora et al., 2017). A concomitant increase of the nuclear volume of the MeMC during these early developmental steps may reflect a change in the epigenetic landscape. Indeed, specific chromatin decondensation and reprogramming were observed during MeMC differentiation in Arabidopsis (She et al., 2013). Several mutants also suggest that epigenetic pathways may restrict expansion of $L 2$ cells in general (Armenta-Medina et al., 2011). For example, mutations in ARGONAUTE 9 (AGO9), RNA-DEPENDENT POLYMERASE 6 (RDR6), and SUPPRESSOR OF GENE SILENCING 3 (SGS3), among other RNA-directed DNA methylation (RdDM) silencing components, result in the simultaneous expansion of multiple $L 2$ cells adjoining the MeMC in Arabidopsis (Fig. 3A; Olmedo-Monfil et al., 2010). While RDR6 is involved in the biogenesis of siRNAs (Peragine et al., 2004), AGO family proteins bind diverse small RNA (sRNA) molecules and induce silencing of complementary sequences by post-transcriptional gene silencing or DNA methylation (Fang and Qi, 2016). Recently, multiple MeMC-like cells were also reported in mutants of the THO/TREX complex genes (TEX1, HPR1, and THO6) in Arabidopsis. The THO complex is involved in the biogenesis of TAS3-derived trans-acting siRNA (ta-siRNA) molecules that spatially restrict the expression of the AUXIN RESPONSE FACTOR 3 (ARF3) gene to the chalazal region of the ovule, while TEX1 is localized inthe nuclei of the epidermal cell layer (Fig. 3A; Su et al., 2017).These results suggest that sRNA-guided repression of specifictarget genes in the young ovule limits the capacity for L2 cellsto expand and prevents them from assuming germline fate. 
AGO9 preferentially binds 24 nucleotide siRNAs derived from transposable elements (OlmedoMonfil et al., 2010) and has been observed in cytoplasmic foci of most somatic cells in the ovule primordia and in the nucleus of the MeMC (Rodríguez-Leal et al., 2015; Su et al., 2017). AGO9 belongs to the $A G O 4$ clade, and mutations in the remaining $A G O 4$ clade members (AGO4, AGO6, and AGO8) also show multiple enlarged germline-like ovule cells (Fig. 3A). This is not the case for other ovule-expressed AGOs such as AGO1, AGO5, and AGO10 (Tucker et al., 2012a; Hernandez-Lagana et al., 2016). Notably, the combination of ago4 and ago9 mutants leads to an increased frequency of somatic cells showing aberrant expansion in the ovule primordia, suggesting that members of the AGO4 clade may act on similar targets (HernandezLagana et al., 2016). Interestingly, variation is observed in the number of L2 cells that 'naturally' enlarge during ovule development, suggesting that the contribution of epigenetic pathways may vary between ecotypes. This is often accompanied by variations in the expression pattern and localization of AGO9, indicating that differences in upstream regulators or interacting partners might contribute to natural variability in germline initiation potential (Rodríguez-Leal et al., 2015).

In addition to their role in Arabidopsis, AGO proteins have been shown to function during megasporogenesis in diverse species, although the timing and role of homologous genes sometimes differs. For example, the $A G O 104$ gene from maize is related to $A G O 9$ and is similarly expressed in somatic cells surrounding the female germline (Singh et al., 2011). However, AGO104 acts to repress somatic cell fate in the germline, and mutants show alterations in chromatin condensation, spindle formation, and chromosome segregation. DNA methylation analysis suggests that AGO104 is involved in non-CG methylation in heterochromatin (Singh et al., 2011), which may establish an epigenetic landscape that is essential for subsequent female germline development. Another conserved AGO protein, AGO5, accumulates in the cytoplasm of Arabidopsis nucellus cells that also express AGO9, but loss-of-function mutants show no obvious reproductive phenotype (Tucker et al., 2012a). Curiously, a truncated semi-dominant AGO5 protein that lacks the catalytic PIWI-domain appears to affect the transition to megagametogenesis in the functional megaspore (Fig. 1), independent of AGO9 (Olmedo-Monfil et al., 2010; Tucker et al., 2012a). A similar phenotype was observed using P1/Hc-Pro, a viral suppressor protein that binds siRNA and inhibits AGOdependent pathways (Kasschau et al., 2003; Tucker et al., 2012a). In rice, alterations of chromosome condensation were observed through mutation of the AGO gene, MEIOSIS ARRESTED AT LEPTOTENE (MEL1), which is phylogenetically closest to the AGO group of AGO5. Chromosome condensation is arrested during meiosis in mel1 mutants (Nonomura et al., 2007), while MEL1 protein is located in the cytoplasm of the germ cells and preferentially binds 21 nucleotide phase siRNA (Komiya et al., 2014).

In summary, these studies suggest that several sRNA-related pathways have repressive functions during distinct stages of germline development. Although there is evidence of diversified functions in different species, the role of AGO proteins and SRNAs appears to be a fundamental requirement for correct germline specification. One key mechanistic question that remains unanswered is how these pathways inhibit growth/expansion of sub-epidermal cell types while selectively allowing expansion of a single germline cell (MeMC).

\section{Cell competency factors are required for germline formation}

Additional regulatory pathways contributing to megasporogenesis have been revealed via mutants that fail to differentiate an MeMC or, similar to the epigenetic pathways described above, produce additional MeMC-like cells. One of the earliest mutants described that shows 
defective MeMC cell differentiation is Arabidopsis nozzle/sporocyteless ( $n z z / s p l)$ (Schiefthaler et al., 1999; Yang et al., 1999). Normal female and male sporogenesis are blocked in $n z z / s p l$ mutants, meaning that plants are unable to differentiate any MiMC or MeMC. Mutations also affect surrounding somatic cells, since development of the anther wall is blocked and the ovule nucellus forms an elongated finger-like structure. The NZZ/SPL gene, which encodes a nuclear protein related to MADS-box transcription factors, appears to be expressed in several ovule tissues including the germline during sporogenesis (Fig. 3B; Schiefthaler et al., 1999; Yang et al., 1999). While the SPL promoter monitored by $\beta$-glucuronidase (GUS) activity is observed at the micropylar end of the ovule throughout germline development (Yang et al., 1999), in situ hybridization shows NZZ/SPL expression in the ovule primordia and later in the integuments and weakly in the MeMC (Schiefthaler et al., 1999; Balasubramanian and Schneitz, 2000). The GUS expression pattern from an NZZ-GUS reporter gene is broader and is also observed in the funiculus and chalaza (Ito et al., 2004). Despite reports suggesting otherwise, the cell typespecific requirements for $N Z Z / S P L$ function remain unclear.

Recently, orthologues of the Arabidopsis NZZ/SPL gene have been reported in important food crops such as the monocot, rice (Ren et al., 2018), and the eudicots, tomato (Rojas-Gracia et al., 2017) and cucumber (Liu et al., 2018). Although overall sequence similarity is limited, all three genes show conservation in regions encoding the SPL, NLS, and EAR motifs. Expression of the NZZ/SPL gene in rice and tomato is observed in male and female tissues, and mutations produce defective stamens and ovules. Interestingly, while the formation of the MiMC and MeMC is affected in the tomato hydra (nzz/spl) mutant (Rojas-Gracia et al., 2017), female sporogenesis is not obviously affected in the rice Ossp/ mutant, which successfully produces an MeMC in the ovule and only arrests during the later developmental process of meiosis (Ren et al., 2018). A molecular function for NZZ/SPL has only recently been reported in Arabidopsis, suggesting that it may act as a transcriptional co-repressor (Chen et al., 2014; Wei et al., 2015). In both male and female sporogenesis, NZZ/ SPL uses the EAR motif to recruit a TOPLESS/TOPLESSRELATED (TPL/TPR) and histone deacetylase (HDAC) complex to inhibit CINCINNATA (CIN)-like TEOSINTE BRANCHED1/CYCLOIDEA/PCF (TCP) transcription factors, thereby promoting meiotic fate in the anther and ovule (Chen et al., 2014; Wei et al., 2015). In rice, OsSPL also interacts with TPL and TCP in the anther (Ren et al., 2018). These studies provide support for a generally conserved role of the NZZ/SPL gene.

Another study related to disruption of germline development in Arabidopsis investigated ovule phenotypes in wuschel (wus), windhose1-windhose2 (wih1 wih2), and tornado (trn) mutants (Fig. 3B; Gross-Hardt et al., 2002; Lieber et al., 2011). At the molecular level, NZZ/SPL appears to promotes expression of WUS in the nucellus, which in turn up-regulates expression of the small peptides WIH1 and WIH2 (Lieber et al., 2011). WIH1/2 genes act downstream of WUS, and double mutants of both genes show defective megasporogenesis in which $\sim 30 \%$ of ovules fail to produce an MeMC (Fig. 3B). Similar phenotypes were also observed in trn1 and trn2 mutants (Lieber et al., 2011). In contrast to NZZ/SPL, WUS mRNA and protein have only been observed in the nucellar cells surrounding the MeMC during ovule development (Zhao et al., 2017).

\section{Multiple inputs contribute to MeMC identity}

Genes such as NZZ/SPL and WUS presumably act upstream of factors involved in the establishment and/or maintenance of MeMC fate. Some of these factors may have been revealed through transcriptomic analysis of different ovule cell types. For example, the first 
transcriptomic analysis of the Arabidopsis MeMC and surrounding nucellar cells using laser capture microdissection (LCM) revealed an enrichment of transcriptional regulators and RNA helicases in the MeMC transcriptome. This led to the discovery of the $\operatorname{MNEME}(m e m)$ gene, encoding an RNA helicase that is expressed in the germline from where it restricts germline identity in surrounding cells (Schmidt et al., 2011). Mutations in mem lead to the formation of multiple germline-like cells in the L2 layer (somewhat reminiscent of ago9) and show epigenetic perturbations in gametophytic nuclei (Schmidt et al., 2011). Although MEM has not been directly linked to the RdDM pathway, it is tempting to speculate that they may regulate similar targets.

An enrichment of transcriptional regulators, including WUS and NZZ/SPL, was also reported in a second LCM-based transcriptional study of the Arabidopsis nucellus (Tucker et al., 2012a). In total, $\sim 440$ genes were identified that are significantly up-regulated in the nucellus relative to the rest of the ovule, reflecting a diversity of cell type-specific expression patterns in the epidermis, functional megaspore, and proximal nucellus. Another study analysed the transcriptome of the $n z z / \mathrm{sp} /$ mutant, and identified four key genes involved in meiosis; Atg04880, At1g13710, At1g13870, and At2g33640 (Zhao et al., 2014). Further characterisation of At1g13710, which encodes a cytochrome P450 monoxygenase named KLUH (KLU) (Anastasiou et al., 2007; Adamski et al., 2009), revealed a role in chromosome pairing during female meiosis (Zhao et al., 2014). Similar anomalies were also reported in mutants of ACTIN RELATED PROTEIN 6 (ARP6), which is a component of the chromatin remodelling SWR1 complex (Qin et al., 2014). Interestingly, the arp6klu double mutant revealed a genetic interaction between $K L U$ and $A R P 6$ that suggests that they are normally involved in preventing multiple MeMC-like cells from forming in the L2 layer (Fig. 3: Zhao et al., 2018). Further studies, including a transcriptional analysis using wildtype, klu, arp6, and arp6klu plants revealed how the transcription factor, WRKY28, which is exclusively expressed in the L2 cells adjacent to the MeMC, acts to repress germline fate. The expression of WRKY28 is controlled by the deposition of the histone variant H2A.Z mediated by SWR1 (Fig. 3C). H2A.Z deposition is dependent on the non-cell-autonomous function of $K L U$, which is expressed in the chalaza and inner integument of the ovule primordia (Fig. 3C; Zhao et al., 2018).

\section{The capacity to maintain multiple germline cells varies between species and mutants}

Other components of germline formation may have been revealed in monocot systems. In rice, one pathway that prevents cells from entering into male and female sporogenesis involves the leucine-rich repeat receptor-like kinase MULTIPLE SPOROCYTE (MSP1), since msp1 mutants produce multiple MeMCs and MiMCs (Nonomura et al., 2003). The TPD1-like protein of rice, TAPETUM DETERMINANT1/ MICROSPORELESS 2 (OsTLD1A/MIL2), binds to MSP1 in yeast and is co-expressed in somatic cells surrounding the MiMC and MeMC. OsTLD1A-RNAi lines only phenocopy msp1 in the ovule (Zhao et al., 2008; Hong et al., 2012), suggesting the existence of alternative interacting partners of MSP1 in the anther. Similar protein pairs (EXS/EMS1- TPD1) have been reported in Arabidopsis (Zhao et al., 2002; Canales et al., 2002; Yang et al., 2003, 2005; Jia et al., 2008) and maize (e.g. MAC1, an orthologue of rice TDL1A; Sheridan et al., 1996, 1999; Wang et al., 2012), while an MSP1 homologue has been revealed through transcriptome profiling of the maize anther (Ma et al., 2007). These studies suggest that in addition to $N Z Z / S P L$ and its co-repressors, conserved receptor- ligand pathways contribute to megasporogenesis and microsporogenesis in multiple species. How these transcription factor and receptor pathways interact remains unclear, since the identification of targets, particularly in the ovule, is yet to be elucidated. 
One curious finding is that mutants showing extra 'germlinelike' cells exhibit key differences in their ability to enter meiosis and/or produce a female gametophyte. For example, the extra germline-like cells in Arabidopsis RdDM mutants typically fail to enter meiosis and infrequently initiate gametophyte development (see Pinto et al., 2019 for a review). In Arabidopsis tex 1 and tas3 mutants, the extra cells occasionally start dividing as a gametophyte (Su et al., 2017). Contrasting this, the rice msp1 mutant (Nonomura et al., 2003) and maize mac1 mutant (Sheridan et al., 1996) produce extra germline cells in the ovule that initiate meiosis and contribute to the formation of multiple disorganized gametophytes. It is unclear why this capacity to initiate meiosis varies between species and mutants. It may simply relate to different roles of the receptor-ligand EXS/EMS1 and RdDM pathways in female germline development. For example, RdDM pathways may fine-tune the 'archesporial state' to limit the pool of archespores, while EXS/ EMS1 pathways may influence both cell identity and competency, providing a capacity to produce multiple archespores and subsequently MeMC. An alternative possibility indirectly raised by Nonomura et al. (2003) is that the enlarged nucellus in rice and maize provides a more suitable environment to support development of multiple MeMCs, somewhat reminiscent of the multi-MeMC phenotypes observed in Trimenia and Gnetum (Fig. 2). Based on the large size of the cereal nucellus (Wilkinson and Tucker, 2017), one could envisage it provides more nutritional support or more 'organizer' cells that are capable of producing signals that stimulate entry into meiosis. If such a stimulatory factor does exist, it must still be present to some degree in RdDM mutants of Arabidopsis, which still produce one fully functional MeMC that is capable of entering meiosis.

Several components of this 'meiotic competency' may have been revealed through study of cell cycle mutants. The triple mutant of $K R P$ [interactor/inhibitor of cyclin-dependent kinase (CDK)/kip-related proteins] genes, krp4krp6krp7, produces multiple MeMCs as a result of mitotic division of the initial MeMC, which fails to directly enter meiosis (Fig. 3C; Zhao et al., 2017). A similar effect was found in the mutant of RETINOBLASTOMA-RELATED1 (RBR1), a key cell cycle regulator that is a target of CDKA:1. RBR1, a transcriptional repressor, binds the promoter of WUS to induce direct downregulation (Zhao et al., 2017). While WUS is observed in the L1 layer of the nucellus in the wild type, WUS was observed in the MeMCs of krp4krp6krp7 and rbr1 mutants, and depletion of WUS limits the formation of multiple MeMCs in the rbr1 background. Intriguingly, ectopic expression of WUS in the MeMC (of wild-type ovules) appears to have no effect, suggesting that the normal function of WUS is to organize developmental signals from somatic cells to the germline. These signals may be conserved between male and female tissues, but regulated by different factors, since multiple MiMCs were also observed in the anther of krp4krp6krp7 where WUS is not normally expressed (Zhao et al., 2017).

ICK/KRPs also appear to function redundantly to restrict MeMC formation to one cell; the inactivation of seven ICK/KRPs led to the formation of multiple MeMCs in random positions, suggesting the loss of a positional signal in addition to de-regulated WUS (Cao et al., 2018). The canonical E2Fs, core cell cycle regulators, are also involved in this pathway. The e2fa e2fc e2fc triple mutant was reported to produce multiple MeMCs, but these may actually reflect multiple megaspores that failed to degenerate during functional megaspore selection (Yao et al., 2018). Taken together, these findings detail a range of pathways involved in the molecular control of germline formation and progression. Importantly, links are emerging between developmental regulators (e.g. WUS) and essential cellular pathways (e.g. core cell cycle machinery such as RBR1 and the ICK/KRPs), providing novel insight into the molecular requirements for germline initiation. Despite this, the nature of the signals that facilitate 
differentiation into a fully functional MeMC remains unknown. One possibility, based on studies from a number of species, is that phytohormones are involved.

\section{Megasporogenesis is highly polarized by auxin and cytokinin maxima}

Phytohormones act as a key player in physiological processes during plant development, in particular by providing positional information that supports localized differentiation events (van den Berg et al., 1995). During gynoecium development, the pattern of auxin and cytokinin distribution is complementary and, while auxin is observed distally, cytokinin distribution is proximal (Marsch-Martínez et al., 2012; Schaller et al., 2015). Similarly, distal auxin and proximal cytokinin distribution polarizes ovule primordia development (see Shirley et al., 2019 for a recent review). In brief, the number of ovule primordia is reduced by inhibition of a regulator of polar auxin transport Pin-formed 1 (PIN1) (Okada et al., 1991) or by mutation of a cytokinin receptor (Riefler et al., 2006; Kinoshita- Tsujimura and Kakimoto, 2011). In contrast, the number of ovule primordia is increased in mutants of a cytokinin oxidase/ dehydrogenasedeactivating enzyme (Bartrina et al., 2011). Importantly, Bencivenga et al. (2012) linked the two hormones in the ovule and showed that PIN1 expression is controlled by cytokinin.

The polarized accumulation of both phytohormones continues during megasporogenesis, and appears to be dependent upon a combination of local biosynthesis and transport. The TRYPTOPHAN AMINOTRANSFERASE OF ARABIDOPSIS 1 (TAA1) gene from Arabidopsis encodes a protein involved in the biosynthesis of auxin (Zhao, 2012). During early ovule development, TAA1 is expressed in the inner integument and funiculus (Ceccato et al., 2013). Contrasting this, auxin accumulates in the tip of the nucellar epidermis (based on the synthetic auxin sensor, DR5; Fig. 4), most likely via PIN1 (Benková et al., 2003; Pagnussat et al.,2009) and PIN3 (Ceccato et al., 2013) expression in the epidermis and recycling downwards towards the funiculus. On the other hand, cytokinin has been observed in the basal part of the ovule (Fig. 4; Zurcher et al., 2013). Thus, the female germline in Arabidopsis develops while polarized by somatic auxin and cytokinin. Interestingly, the distal auxin maximum in the nucellus overlaps closely with a number of key regulators of female germline development including WUS, AGO5, and WIH1/2 (Lieber et al., 2011; Tucker et al., 2012a; Zhao et al., 2017). This auxin maximum was not observed in nzz/sp/ ovules, consistent with NZZ/SPL being required for PIN1 expression (Fig. 3B; Bencivenga et al., 2012).

A distal auxin maximum was also reported in the eudicot Hieracium (Tucker et al., 2012b) and in the monocot maize (Forestan et al., 2012; Lituiev et al., 2013), and proposed in the early divergent angiosperms Annona cherimola (cherimoya) and Persea americana (avocado) (Lora et al., 2017). These studies suggest a conserved hormonal microenvironment (in terms of auxin transport at least) around the female germline in flowering plants and a role for the nucellar epidermis as a signalling conduit. Remarkably, this does not seem to be adversely influenced by the number of layers that separate the MeMC from the tip of the ovule. Maize, cherimoya, and avocado produce a crassinucellate ovule compared with the tenuinucellate ovule of Arabidopsis and Hieracium (Fig. 2), meaning they show differences in the number of cell layers surrounding the female germline. Irrespective, both types of ovules show similar auxin accumulation. Interestingly, while only one PIN1 gene has been identified in Arabidopsis and cherimoya, two PIN1 (PIN1.1 and PIN1.2) orthologues have been identified in avocado. The PIN1 orthologue of cherimoya is observed in all 'epidermal' nucellus layers surrounding the female germline, while expression of avocado PIN1.1 is only observed in cell layers surrounding the MeMC. However, the expression of a PIN11.1 orthologue (also called SISTER 
OF PIN1 in Arabidopsis; O'Connor et al., 2014) in avocado is mainly observed in the distal cell layers of the nucellus and complements the PIN1.1 expression in the neighbouring cell layers around the MeMC (Lora et al., 2017). How auxin transport and response might be achieved during female germline development in gymnosperms such as Larix, Gnetum, Pinus, or Gingko that produce even more layers between the germline and tip of the ovule (Fiordi, 1987) is currently unknown. While the central location of the MeMC is consistent, the 'depth' at which it is specified and/or develops within the nucellus must require specialized inputs depending on the species.

\section{Cell wall components may allow germline cells to enter distinct developmental pathways}

The defined position of the MeMC, the polarized nature of its meiotic products, and the involvement of distinct epidermal and subepidermal cells in specification suggest a need to precisely control the flow of information during megasporogenesis. The cell wall and its constituent polysaccharides, glycoproteins, and phenolic compounds provide an ideal matrix to regulate signal flow and facilitate changes in cell identity (reviewed in Tucker and Koltunow, 2014; Tucker et al., 2018). For example, callose ( $1 \rightarrow 3)$ - $\beta$-d-glucan has been identified as a molecular filter that can regulate the movement of molecules through plasmodesmata (Maule et al., 2012). In angiosperms, callose generally appears around the MiMC just before meiosis (Blackmore et al., 2007), and is typically observed around the MeMC and the megaspores of the ovule (Tucker et al., 2001; Musiał et al., 2015). Deposition in the MeMC wall precedes the initiation of meiosis, and may provide a transient molecular filter to restrict crosstalk with surrounding somatic cells. Plasmodesmata are observed in the MeMC and the lateral and chalazal side of the functional megaspore, but are absent in the functional megaspore wall that is adjacent to the degenerating megaspores of Arabidopsis (Bajon et al., 1999). A recent study in apomictic Hieracium revealed localized callose deposits between the functional megaspore and dormant aposporous initials (ectopic functional megaspore-like cells, somewhat similar to those observed in RdDM mutants in Arabidopsis), potentially limiting access to signals that facilitate progression though the S/G2 phase of the cell cycle and the continuation of germline development (Juranic et al., 2018). In gymnosperms, while callose has scarcely been observed around the MeMC and/or during meiosis (Rodkiewicz, 1970; Rafińska and Bednarska, 2011), the MeMC shows a thickening of the cell wall such that plasmodesmata are occluded during meiosis (Fiordi and Maugini, 1977; Fiordi et al., 1988, 1991). In contrast, the gymnosperm Taxus bacatta shows unchanged wall thickenings near plasmodesmata, and this coincides with the appearance of up to four functional megaspores (Fiordi et al., 1991).

Another prominent yet confounding component of the female germline cell wall are the arabinogalactan proteins (AGPs). These glycoproteins are ubiquitous in plants and contain an extremely variable sugar chain that can be detached from the cell wall and secreted to the apoplast (Majewska-Sawka and Nothnagel, 2000; Ellis et al., 2010), possibly acting as a signal for cell-cell communication. During Arabidopsis ovule development, AGP18 is required for selection of the functional megaspore (Demesa-Arévalo and Vielle-Calzada, 2013). Although AGP18 expression is only observed in the basal part of the integument during meiosis, overexpression results in survival of multiple megaspores after meiosis, suggesting that the transcript may be a non-cell-autonomous component of megaspore selection (Demesa-Arévalo and Vielle-Calzada, 2013). AGP localization, revealed using monoclonal antibodies such as JIM8 and JIM13, is dynamic during ovule development and varies between species. For example, although AGP epitopes are not detected in the Arabidopsis MeMC, AGPs are observed in the 
MeMC of strawberry (Szczuka and Leszczuk, 2017; Leszczuk and Szczuka, 2018) and Hieracium species (Juranic et al., 2018). Moreover, AGPs have been observed in the cell wall of the MeMCs in the crassinucelate ovule of $A$. cherimola and P. americana (Lora et al., 2017).

These studies of the cell wall provide some insight into compositional changes that occur during the acquisition of germline identity. However, it is unclear how components such as callose and AGPs are integrated into the network of typical primary cell wall polysaccharides such as cellulose, pectin, and xyloglucan, and how they contribute to the process of MeMC growth. Although evidence supports the presence of these polysaccharides in ovule cells of several species (Lora et al., 2017; Juranic et al., 2018), their precise role has yet to be elucidated. Converging signals and mechanical changes may promote germline expansion As discussed above, rapid expansion of the primary germline cell (compared with surrounding somatic cells) is a feature of MeMC maturation in many divergent plant species (Fig. 2; Lora et al., 2017). The signal source for this growth could be adjacent nucellar cells, which provide a positional cue that prompts the change in cell size. As described above, AGO9 represses ectopic 'MeMC' growth and division through an sRNA pathway, possibly acting from nongermline cells to inactivate genes involved in mitosis (Fig. 3; Olmedo-Monfil et al., 2010). At the same time, auxin forms a local maximum in nucellar cells, just above the distal end of the MeMC (Fig. 4; Benková et al., 2003; Pagnussat et al., 2009). In maize, a similar auxin maximum in the ovule primordium is observed, and the distal end of the maize MeMC expands more significantly than its proximal end (Lituiev et al., 2013). Auxin can be a trigger for either cell division or cell expansion (Perrot-Rechenmann, 2010), and in the context of MeMC development it seems feasible that auxin might result in cell expansion via inhibition of a cell division pathway. The arrested development of the germline precursor in the Arabidopsis $n z z / s p /$ mutant might simply be a result of disordered auxin distribution, since NZZ/SPL acts upstream of PIN1 (Bencivenga et al., 2012). In general terms, auxin induces the acidification of the extracellular space, and activation of cell wall relaxants such as expansins and xyloglucan endotransglycosylase/hydrolases (XTHs) (Perrot-Rechenmann, 2010). The auxin maximum in the ovule primordium could provide similar stimuli to the MeMC. Accordingly, the accumulation of methylesterified homogalacturonan in the cell wall of the MeMC and adjacent cells also indicates the decrease of tissue rigidity in this area (Fig. 4; Pérez-Pastrana et al., 2018).

Although the surrounding somatic cells must create a favourable environment for the MeMC to expand, this expansion event is not just passively driven. The rice msp1 mutant allows multiple germline precursors to develop, and each MeMC-like cell expands to a larger volume than somatic cells, giving rise to a wider nucellus in the mutant (Nonomura et al., 2003). Could positive regulators function within the MeMC to promote its expansion? As MeMC cell expansion progresses, the cell produces a large number of organelles and establishes a cellular polarity, with the nucleus localized at a more proximal position, most of the plastids in the area beneath the nucleus, and cisternae of endoplasmic reticulum (ER) arranged in a parallel manner in the distal part of the cell (Stewart and Gifford, 1967; Russell, 1979; Bajon et al., 1999; Siddiqi et al., 2000). Only a few small vacuoles are detected in the MeMC, which might not provide sufficient oncotic pressure to drive cell expansion. This indicates that the expansion requires coordination with surrounding cells, as well as the complex activities of pre-meiotic preparation and epigenetic reprogramming. The polarized distribution of the ER is intriguing, suggesting a potential protein and/or mRNA gradient in the MeMC and local regulators of cell behaviour. It is still unclear if there is any connection between cell expansion 
and organelle polarization, but disturbing specific microtubule or F-actin-binding proteins involved in organelles movement may give clues to this puzzle.

\section{Conclusions}

Female germline development in plants is a fascinating form of cell differentiation. The specification of the MeMC is a remarkably conserved process across diverse plant species, one that appears to be independent of considerable natural variation in nucellus size and epidermal layer number. Important recent findings have revealed a new set of genes supporting MeMC formation that are expressed outside of the germline, reaffirming the role of signals in positioning the germline and influencing its development. These signals involve RdDM, receptor- ligand complexes, and cell cycle- and chromatin-related machinery, which, along with several key unknown factors, appear to provide the capacity to differentiate and enter meiosis. Importantly, the point at which these pathways merge remains elusive, as does the mechanistic basis for selective growth of the MeMC. This provides scope for future studies into MeMC development at an even more refined level than those described to date.

\section{Acknowledgements}

We apologize to authors whose work we did not cite in this review. We thank Thomas Laux, Marta Mendes, Lucia Colombo, and Neil Shirley for stimulating discussions, and Sara Pinto for the DIC images used in Fig. 1. We acknowledge funding from the Australian Research Council (FT140100780 and DP180104092) to MRT and the Ministry of Science, Innovation and Universities of Spain (AGL2015-74071-JIN) to JL.

\section{References}

Adamski NM, Anastasiou E, Eriksson S, O'Neill CM, Lenhard M. 2009. Local maternal control of seed size by KLUH/CYP78A5-dependent growth signaling. Proceedings of the National Academy of Sciences, USA 106, 20115-20120.

Anastasiou E, Kenz S, Gerstung M, MacLean D, Timmer J, Fleck C, Lenhard M. 2007. Control of plant organ size by KLUH/CYP78A5- dependent intercellular signaling. Developmental Cell 13, 843-856.

Arabidopsis Genome Initiative. 2000. Analysis of the genome sequence of the flowering plant Arabidopsis thaliana. Nature 408, 796-815.

Armenta-Medina A, Demesa-Arévalo E, Vielle-Calzada JP. 2011. Epigenetic control of cell specification during female gametogenesis. Sexual Plant Reproduction 24, 137-147.

Bachelier JB, Friedman WE. 2011. Female gamete competition in an ancient angiosperm lineage. Proceedings of the National Academy of Sciences, USA 108, 12360-12365.

Bajon C, Horlow C, Motamayor JC, Sauvanet A, Robert D. 1999. Megasporogenesis in Arabidopsis thaliana L.: an ultrastructural study. Sexual Plant Reproduction 12, 99-109.

Balasubramanian S, Schneitz K. 2000. NOZZLE regulates proximal- distal pattern formation, cell proliferation and early sporogenesis during ovule development in Arabidopsis thaliana. Development 127, 4227-4238.

Bartrina I, Otto E, Strnad M, Werner T, Schmülling T. 2011. Cytokinin regulates the activity of reproductive meristems, flower organ size, ovule formation, and thus seed yield in Arabidopsis thaliana. The Plant Cell 23, 
69-80.

Bäurle I, Dean C. 2006. The timing of developmental transitions in plants. Cell 125, 655-664.

Bencivenga S, Simonini S, Benková E, Colombo L. 2012. The transcription factors BEL1 and SPL are required for cytokinin and auxin signalling during ovule development in Arabidopsis. The Plant Cell 24, 2886-2897.

Benková E, Michniewicz M, Sauer M, Teichmann T, Seifertová D, Jürgens G, Friml J. 2003. Local, efflux-dependent auxin gradients as a common module for plant organ formation. Cell 115, 591-602.

Blackmore S, Wortley AH, Skvarla JJ, Rowley JR. 2007. Pollen wall development in flowering plants. New Phytologist 174, 483-498.

Canales C, Bhatt AM, Scott R, Dickinson H. 2002. EXS, a putative LRR receptor kinase, regulates male germline cell number and tapetal identity and promotes seed development in Arabidopsis. Current Biology 12, 1718-1727.

Cao L, Wang S, Venglat P, Zhao L, Cheng Y, Ye S, Qin Y, Datla R, Zhou Y, Wang H. 2018. Arabidopsis ICK/KRP cyclin-dependent kinase inhibitors function to ensure the formation of one megaspore mother cell and one functional megaspore per ovule. PLoS Genetics 14, e1007230.

Cass DD, Peteya DJ, Robertson BL. 1986. Megagametophyte development in Hordeum vulgare. 2. Later stages of wall development and morphological aspects of megagametophyte cell differentiation. Canadian Journal of Botany 64, 2327-2336.

Ceccato L, Masiero S, Sinha Roy D, Bencivenga S, Roig-Villanova I, Ditengou FA, Palme K, Simon $R$, Colombo L. 2013. Maternal control of PIN1 is required for female gametophyte development in Arabidopsis. PLoS One 8, e66148.

Chen G-H, Sun J-Y, Liu M, Liu J, Yang W-C. 2014. SPOROCYTELESS is a novel embryophytespecific transcription repressor that interacts with TPL and TCP proteins in Arabidopsis. Journal of Genetics and Genomics 41, 617-625.

Demesa-Arévalo E, Vielle-Calzada JP. 2013. The classical arabinogalactan protein AGP18 mediates megaspore selection in Arabidopsis. The Plant Cell 25, 1274-1287.

Di Laurenzio L, Wysocka-Diller J, Malamy JE, Pysh L, Helariutta Y, Freshour G, Hahn MG, Feldmann KA, Benfey PN. 1996. The SCARECROW gene regulates an asymmetric cell division that is essential for generating the radial organization of the Arabidopsis root. Cell 86, 423433.

Ellis M, Egelund J, Schultz CJ, Bacic A. 2010. Arabinogalactan-proteins: key regulators at the cell surface? Plant Physiology 153, 403-419.

Endress PK. 2011. Angiosperm ovules: diversity, development, evolution. Annals of Botany $107,1465-1489$.

Fang X, Qi Y. 2016. RNAi in plants: an argonaute-centered view. The Plant Cell 28, 272-285.

Fiordi AC. 1987. Megasporogenesis in gymnosperms: aspects of the cytoplasm and the cell walls. Atti della Societá Toscana di Scienze Naturali, Memorie, Serie B 94, 163-179. 
Fiordi AC, Lippi MM, Maugini E. 1988. On the megasporogenesis in Larix leptolepis (Sieb. et Zucc.) Gordon (Pinaceae). Caryologia 41, 209-225.

Fiordi AC, Lippi MM, Tani G. 1991. Ultrastructural observations on the megasporocyte of Taxus baccata L. (Taxaceae) in relation to megaspore behaviour. Caryologia 44, 45-53.

Fiordi AC, Maugini E. 1977. On the megasporogenesis in Chamaecyparis lawsoniana Parl. Caryologia 30, 77-96.

Forestan C, Farinati S, Varotto S. 2012. The maize PIN gene family of auxin transporters. Frontiers in Plant Science 3, 16.

Gross-Hardt R, Lenhard M, Laux T. 2002. WUSCHEL signaling functions in interregional communication during Arabidopsis ovule development. Genes \& Development 16, 1129-1138.

Grossniklaus U. 2011. Plant germline development: a tale of cross-talk, signaling, and cellular interactions. Sexual Plant Reproduction 24, 91-95.

Hernández-Lagana E, Rodríguez-Leal D, Lúa J, Vielle-Calzada JP. 2016. A multigenic network of ARGONAUTE4 clade members controls early megaspore formation in Arabidopsis. Genetics 204, 1045-1056.

Hong L, Tang D, Shen Y, Hu Q, Wang K, Li M, Lu T, Cheng Z. 2012. MIL2 (MICROSPORELESS2) regulates early cell differentiation in the rice anther. New Phytologist 196, 402-413.

Ito T, Wellmer F, Yu H, Das P, Ito N, Alves-Ferreira M, Riechmann JL, Meyerowitz EM. 2004. The homeotic protein AGAMOUS controls microsporogenesis by regulation of SPOROCYTELESS. Nature 430, 356-360.

Jia G, Liu X, Owen HA, Zhao D. 2008. Signaling of cell fate determination by the TPD1 small protein and EMS1 receptor kinase. Proceedings of the National Academy of Sciences, USA 105, 2220-5.

Juranić M, Tucker MR, Schultz CJ, Shirley NJ, Taylor JM, Spriggs A, Johnson SD, Bulone V, Koltunow AM. 2018. Asexual female gametogenesis involves contact with a sexually-fated megaspore in apomictic Hieracium. Plant Physiology 177, 1027-1049.

Kasschau KD, Xie Z, Allen E, Llave C, Chapman EJ, Krizan KA, Carrington JC. 2003. P1/HC-Pro, a viral suppressor of RNA silencing, interferes with Arabidopsis development and miRNA function. Developmental Cell 4, 205-217.

Kennell JC, Horner HT. 1985. Megasporogenesis and megagametogenesis in soybean, Glycine max. American Journal of Botany 72, 1553-1564.

Kinoshita-Tsujimura K, Kakimoto T. 2011. Cytokinin receptors in sporophytes are essential for male and female functions in Arabidopsis thaliana. Plant Signaling \& Behavior 6, 66-71.

Koizumi K, Hayashi T, Wu S, Gallagher K. 2012. The SHORT-ROOT protein acts as a mobile dosedependent signal in the patterning of the ground tissue. Proceedings of the National Academy of Sciences, USA 109, 13010-13015.

Koltunow AM, Johnson SD, Bicknell RA. 1998. Sexual and apomictic development in Hieracium. Sexual Plant Reproduction 11, 213-230. 
Komiya R, Ohyanagi H, Niihama M, Watanabe T, Nakano M, Kurata N, Nonomura K-I. 2014. Rice germline-specific Argonaute MEL1 protein binds to phasiRNAs generated from more than 700 lincRNAs. The Plant Journal 78, 385-397.

Leszczuk A, Szczuka E. 2018. Arabinogalactan proteins: immunolocalization in the developing ovary of a facultative apomict Fragaria $x$ ananassa (Duch.). Plant Physiology and Biochemistry $123,24-33$.

Letunic I, Bork P. 2019. Interactive Tree Of Life (iTOL) v4: recent updates and new developments. Nucleic Acids Research doi.org/10.1093/nar/ gkz239.

Lieber D, Lora J, Schrempp S, Lenhard M, Laux T. 2011. Arabidopsis WIH1 and WIH2 genes act in the transition from somatic to reproductive cell fate. Current Biology 21, 1009-1017.

Lituiev DS, Krohn NG, Müller B, et al. 2013. Theoretical and experimental evidence indicates that there is no detectable auxin gradient in the angiosperm female gametophyte.

Development 140, 4544-53.

Liu X, Ning K, Che G, Yan S, Han L, Gu R, Li Z, Weng Y, Zhang X. 2018. CsSPL functions as an adaptor between HD-ZIP III and CsWUS transcription factors regulating anther and ovule development in Cucumis sativus (cucumber). The Plant Journal 94, 535-547.

Lockhart J. 2014. Uncovering male germline development in Arabidopsis: the gametophyte revealed. The Plant Cell 26, 1837.

Lora J, Herrero M, Tucker MR, Hormaza JI. 2017. The transition from somatic to germline identity shows conserved and specialized features during angiosperm evolution. New Phytologist 216, 495-509.

Lu J, Magnani E. 2018. Seed tissue and nutrient partitioning, a case for the nucellus. Plant Reproduction 31, 309.

Ma J, Duncan D, Morrow DJ, Fernandes J, Walbot V. 2007. Transcriptome profiling of maize anthers using genetic ablation to analyse pre-meiotic and tapetal cell types. The Plant Journal $50,637-48$.

Maheshwari P. 1950. An introduction to the embryology of angiosperms. New York: McGrawHill.

Majewska-Sawka A, Nothnagel EA. 2000. The multiple roles of arabinogalactan proteins in plant development. Plant Physiology 122, 3-10.

Marsch-Martínez N, Ramos-Cruz D, Irepan Reyes-Olalde J, Lozano- Sotomayor P, Zúniga-Mayo VM, de Folter S. 2012. The role of cytokinin during Arabidopsis gynoecia and fruit morphogenesis and patterning. The Plant Journal 72, 222-234.

Maule A, Faulkner C, Benitez-Alfonso Y. 2012. Plasmodesmata 'in Communicado'. Frontiers in Plant Science 3, 30.

Musiał K, Kościńska-Pająk M, Antolec R, Joachimiak AJ. 2015. Deposition of callose in young ovules of two Taraxacum species varying in the mode of reproduction. Protoplasma 252, 135144.

Nonomura K-I. 2003. The MSP1 gene is necessary to restrict the number of cells entering into male and female sporogenesis and to initiate anther 
wall formation in rice. The Plant Cell 15, 1728-1739.

Nonomura K, Morohoshi A, Nakano M, Eiguchi M, Miyao A, Hirochika H, Kurata N. 2007. A germ cell specific gene of the ARGONAUTE family is essential for the progression of premeiotic mitosis and meiosis during sporogenesis in rice. The Plant Cell 19, 2583-2594.

O'Connor DL, Runions A, Sluis A, Bragg J, Vogel JP, Prusinkiewicz P, Hake S. 2014. A division in PIN-mediated auxin patterning during organ initiation in grasses. PLoS Computational Biology 10, e1003447.

Okada K, Ueda J, Komaki MK, Bell CJ, Shimura Y. 1991. Requirement of the auxin polar transport system in early stages of arabidopsis floral bud formation. The Plant Cell 3, 677-684.

Olmedo-Monfil V, Durán-Figueroa N, Arteaga-Vázquez M, Demesa- Arévalo E, Autran D, Grimanelli D, Slotkin RK, Martienssen RA,

Vielle-Calzada JP. 2010. Control of female gamete formation by a small RNA pathway in Arabidopsis. Nature 464, 628-632.

Pagnussat GC, AlandeteSaez M, Bowman JL, Sundaresan V. 2009. Auxin dependent patterning and gamete specification in the Arabidopsis female gametophyte. Science 324, 1684-1689.

Pang PP, Meyerowitz EM. 1987. Arabidopsis thaliana: a model system for plant molecular biology. Nature Biotechnology 5, 1177-1181.

Payne T, Johnson SD, Koltunow AM. 2004. KNUCKLES (KNU) encodes a $\mathrm{C} 2 \mathrm{H} 2$ zinc-finger protein that regulates development of basal pattern elements of the Arabidopsis gynoecium. Development 131, 3737-3749.

Peragine A, Yoshikawa M, Wu G, Albrecht HL, Poethig RS. 2004. SGS3 and SGS2/SDE1/RDR6 are required for juvenile development and the production of trans-acting siRNAs in Arabidopsis. Genes \& Development 18, 2368-2379.

Perrot-Rechenmann C. 2010. Cellular responses to auxin: division versus expansion. Cold Spring Harbor Perspectives in Biology 2, a001446.

Pérez-Pastrana J, Islas-Flores I, Bárány I, et al. 2018. Development of the ovule and seed of Habanero chili pepper (Capsicum chinense Jacq.): anatomical characterization and immunocytochemical patterns of pectin methyl-esterification. Journal of Plant Physiology 230, 1-12.

Pinto SC, Mendes MA, Coimbra S, Tucker MR. 2019. Revisiting the female germline and its expanding toolbox. Trends in Plant Science 24, 455-467.

Qin Y, Zhao L, Skaggs MI, et al. 2014. ACTIN-RELATED PROTEIN6 regulates female meiosis by modulating meiotic gene expression in Arabidopsis. The Plant Cell 26, 1612-1628.

Rafińska K, Bednarska E. 2011. Localisation pattern of homogalacturonan and arabinogalactan proteins in developing ovules of the gymnosperm plant Larix decidua Mill. Sexual Plant Reproduction 24, 75-87.

Ren L, Tang D, Zhao T, et al. 2018. OsSPL regulates meiotic fate acquisition in rice. New Phytologist 218, 789-803. 
Riefler M, Novak O, Strnad M, Schmülling T. 2006. Arabidopsis cytokinin receptor mutants reveal functions in shoot growth, leaf senescence, seed size, germination, root development, and cytokinin metabolism. The Plant Cell 18, 40-54.

Rodkiewicz B. 1970. Callose in cell walls during megasporogenesis in angiosperms. Planta 93, 39-47.

Rodríguez-Leal D, León-Martínez G, Abad-Vivero U, Vielle- Calzada JP. 2015. Natural variation in epigenetic pathways affects the specification of female gamete precursors in Arabidopsis. The Plant Cell 27, 1034-1045.

Rojas-Gracia P, Roque E, Medina M, et al. 2017. The parthenocarpic hydra mutant reveals a new function for a SPOROCYTELESS-like gene in the control of fruit set in tomato. New Phytologist 214, 1198-1212.

Rudall PJ. 1997. The nucellus and chalaza in monocotyledons: structure and systematics. Botanical Review 63, 140-181.

Russell SD. 1979. Fine structure of megagametophyte development in Zea mays. Canadian Journal of Botany 57, 1093-1110.

Russell SD. 2001. Female gametogenesis. In: Bhojwani SS, Soh W-Y, eds. Current trends in the embryology of angiosperms. Dordrecht: Springer Netherlands, 67-88.

Russell SD, Jones DS. 2015. The male germline of angiosperms: repertoire of an inconspicuous but important cell lineage. Frontiers in Plant Science 6, 173.

Sarkar AK, Luijten M, Miyashima S, Lenhard M, Hashimoto T, Nakajima K, Scheres B, Heidstra $\mathrm{R}$, Laux T. 2007. Conserved factors regulate signalling in Arabidopsis thaliana shoot and root stem cell organizers. Nature 446, 811-814.

Schaller GE, Bishopp A, Kieber JJ. 2015. The yin-yang of hormones: cytokinin and auxin interactions in plant development. The Plant Cell 27, 44-63.

Schiefelbein J. 2003. Cell-fate specification in the epidermis: a common patterning mechanism in the root and shoot. Current Opinion in Plant Biology 6, 74-78.

Schiefthaler U, Balasubramanian S, Sieber P, Chevalier D, Wisman E, Schneitz K. 1999. Molecular analysis of NOZZLE, a gene involved in pattern formation and early sporogenesis during sex organ development in Arabidopsis thaliana. Proceedings of the National Academy of Sciences, USA 96, 11664-11669.

Schmidt A, Schmid MW, Grossniklaus U. 2015. Plant germline formation: common concepts and developmental flexibility in sexual and asexual reproduction. Development 142, 229-241.

Schmidt A, Wuest SE, Vijverberg K, Baroux C, Kleen D, Grossniklaus U. 2011. Transcriptome analysis of the Arabidopsis megaspore mother cell uncovers the importance of RNA helicases for plant germline development. PLoS Biology 9, e1001155.

Schoof $\mathrm{H}$, Lenhard M, Haecker A, Mayer KF, Jürgens G, Laux T. 2000. The stem cell population of Arabidopsis shoot meristems in maintained by a regulatory loop between the CLAVATA and WUSCHEL genes. Cell 100, 635-644. 
She W, Grimanelli D, Rutowicz K, Whitehead MWJ, Puzio M, Kotlinski M, Jerzmanowski A, Baroux C. 2013. Chromatin reprogramming during the somatic-to-reproductive cell fate transition in plants. Development 140, 4008-4019.

Sheridan WF, Avalkina NA, Shamrov II, Batygina TB, Golubovskaya IN. 1996. The mac1 gene: controlling the commitment to the meiotic pathway in maize. Genetics 142, 1009-1020.

Sheridan WF, Golubeva EA, Abrhamova LI, Golubovskaya IN. 1999. The mac1 mutation alters the developmental fate of the hypodermal cells and their cellular progeny in the maize anther. Genetics 153, 933-941.

Shirley NJ, Aubert M, Wilkinson L, Bird D, Lora J, Yang X, Tucker MR. 2019. Translating auxin responses into ovules, seeds and yield: insight from

Arabidopsis and the cereals. Journal of Integrative Plant Biology 61, 310-336. Siddiqi I, Ganesh G, Grossniklaus U, Subbiah V. 2000. The dyad gene is required for progression through female meiosis in Arabidopsis. Development 127, 197-207.

Singh M, Goel S, Meeley RB, Dantec C, Parrinello H, Michaud C, Leblanc O, Grimanelli D. 2011. Production of viable gametes without meiosis in maize deficient for an ARGONAUTE protein. The Plant Cell 23, 443-458.

Sporne KR. 1969. The ovule as an indicator of evolutionary status in Angiosperms. New Phytologist 68, 555-566.

Stewart KD, Gifford EM. 1967. Ultrastructure of the developing megaspore mother cell of Ginkgo biloba. American Journal of Botany 54, 375-383.

Su Z, Zhao L, Zhao Y, et al. 2017. The THO complex non-cellautonomously represses female germline specification through the TAS3-ARF3 module. Current Biology 27, 1597-1609.

Szczuka E, Leszczuk A. 2017. Localization of arabinogalactan proteins in the cell walls of developing ovule in strawberry (Fragaria $\times$ ananassa Duch.). International Journal of Plant Biolology and Research 5, 1066.

Takaso T, Bouman F. 1986. Ovule and seed ontogeny in Gnetum gnemon L. The Botanical Magazine 99, 241-266.

Tilton VR, Lersten NR. 1981. Ovule development in Ornithogalum caudatum (Liliaceae) with a review of selected papers on angiosperm reproduction. III. Nucellus and megagametophyte. New Phytologist 88, 477-504.

Tucker MR, Araujo AC, Paech NA, Hecht V, Schmidt ED, Rossell JB, De Vries SC, Koltunow AM. 2003. Sexual and apomictic reproduction in Hieracium subgenus Pilosella are closely interrelated developmental pathways. The Plant Cell 15, 1524-1537.

Tucker MR, Koltunow AM. 2014. Traffic monitors at the cell periphery: the role of cell walls during early female reproductive cell differentiation in plants. Current Opinion in Plant Biology $17,137-145$.

Tucker M, Lou H, Aubert M, et al. 2018. Exploring the role of cell wallrelated genes and polysaccharides during plant development. Plants 7, 42 .

Tucker MR, Okada T, Hu Y, Scholefield A, Taylor JM, Koltunow AMG. 2012a. Somatic small RNA pathways promote the mitotic events 
of megagametogenesis during female reproductive development in Arabidopsis. Development 139, 1399-1404.

Tucker MR, Okada T, Johnson SD, Takaiwa F, Koltunow AM. 2012b. Sporophytic ovule tissues modulate the initiation and progression of apomixis in Hieracium. Journal of Experimental Botany 63, 3229-3241.

Tucker MR, Paech NA, Willemse MT, Koltunow AM. 2001. Dynamics of callose deposition and beta-1,3-glucanase expression during reproductive events in sexual and apomictic Hieracium. Planta 212, 487-498.

van den Berg C, Willemsen V, Hage W, Weisbeek P, Scheres B. 1995. Cell fate in the Arabidopsis root meristem determined by directional signalling. Nature 378, 62-65.

Vogler H, Grossniklaus U, Hedhly A. 2017. An introduction to male germline development. New York: Humana Press, 3-15.

Wang C-JR, Nan G-L, Kelliher T, Timofejeva L, Vernoud V, Golubovskaya IN, Harper L, Egger R, Walbot V, Cande WZ. 2012. Maize multiple archesporial cells 1 (mac1), an ortholog of rice $T D L 1 A$, modulates cell proliferation and identity in early anther development. Development 139, 2594-603.

Wei, B-Y, Zhang, J-Z, Pang, C-X, et al. 2015. The molecular mechanism of SPOROCYTELESS/NOZZLE in controlling Arabidopsis ovule development. Cell Research 25, 121134.

Wilkinson LG, Bird DC, Tucker MR. 2018. Exploring the role of the ovule in cereal grain development and reproductive stress tolerance. Annual Plant Reviews doi.org/10.1002/9781119312994.apr0609.

Wilkinson LG, Tucker MR. 2017. An optimised clearing protocol for the quantitative assessment of sub-epidermal ovule tissues within whole cereal pistils. Plant Methods 13, 67.

Yang SL, Jiang L, Puah CS, Xie LF, Zhang XQ, Chen LQ, Yang WC, Ye D. 2005. Overexpression of TAPETUM DETERMINANT1 alters the cell fates in the Arabidopsis carpel and tapetum via genetic interaction with excess microsporocytes1/extra sporogenous cells. Plant Physiology 139, 186-191.

Yang SL, Xie LF, Mao HZ, Puah CS, Yang WC, Jiang L, Sundaresan V, Ye D. 2003. Tapetum determinant1 is required for cell specialization in the Arabidopsis anther. The Plant Cell 15, 2792-2804.

Yang WC, Ye D, Xu J, Sundaresan V. 1999. The SPOROCYTELESS gene of Arabidopsis is required for initiation of sporogenesis and encodes a novel nuclear protein. Genes \& Development 13, 2108-2117.

Yao X, Yang H, Zhu Y, Xue J, Wang T, Song T, Yang Z, Wang S. 2018. The canonical E2Fs are required for germline development in Arabidopsis. Frontiers in Plant Science 9, 638.

Zhao DZ, Wang GF, Speal B, Ma H. 2002. The excess microsporocytes1 gene encodes a putative leucine-rich repeat receptor protein kinase that controls somatic and reproductive cell fates in the Arabidopsis anther. Genes \& Development 16, 2021-2031. 
Zhao L, Cai H, Su Z, et al. 2018. KLU suppresses megasporocyte cell fate through SWR1mediated activation of WRKY28 expression in Arabidopsis. Proceedings of the National Academy of Sciences, USA 115, E526-E535.

Zhao L, He J, Cai H, Lin H, Li Y, Liu R, Yang Z, Qin Y. 2014. Comparative expression profiling reveals gene functions in female meiosis and gametophyte development in Arabidopsis. The Plant Journal 80, 615-628.

Zhao X, Bramsiepe J, Van Durme M, et al. 2017. RETINOBLASTOMA RELATED1 mediates germline entry in Arabidopsis. Science 356, eaaf6532.

Zhao X, de Palma J, Oane R, Gamuyao R, Luo M, Chaudhury A, Hervé P, Xue Q, Bennett J. 2008. OsTDL1A binds to the LRR domain of rice receptor kinase MSP1, and is required to limit sporocyte numbers. The Plant Journal 54, 375-387.

Zhao Y. 2012. Auxin biosynthesis: a simple two-step pathway converts tryptophan to indole-3acetic acid in plants. Molecular Plant 5, 334-338.

Zürcher E, Tavor-Deslex D, Lituiev D, Enkerli K, Tarr PT, Müller B. 2013. A robust and sensitive synthetic sensor to monitor the transcriptional output of the cytokinin signaling network in planta. Plant Physiology 161, 1066-1075. 